\title{
Voltage regulator placement in radial distribution system using plant growth simulation algorithm
}

\author{
P.V.V. Rama Rao $^{1}{ }^{*}$, S. Sivanaga Raju ${ }^{2}$ \\ ${ }^{1 *}$ Department of Electrical \& Electronics Engineering, Arjun College of Technology \& Science, Hyderabad, INDIA \\ ${ }^{2}$ Department of Electrical \& Electronics Engineering, JNTUK College of Engineering, Kakinada, INDIA \\ "Corresponding Author: e-mail: pvvmadhuram@gmail.com, Mobile: +91-9440616698
}

\begin{abstract}
This paper presents selection of optimal locations and sizes of voltage regulators in radial distribution system using Plant Growth Simulation Algorithm (PGSA). Voltage has always been considered as an integral part of the power system response. There are several factors, which contribute to voltage collapse such as increased loading on distribution feeders, reactive power constraints, on load tap changer dynamics and load characteristics. The proposed method for voltage regulator placement is suitable for large radial distribution network. The VR problem consists of two sub problems, that of optimal placement and optimal choice of tap setting. The proposed method deals with initial selection of voltage regulator buses by using power loss indices (PLI). The candidate node identification technique and Plant Growth Simulation Algorithm (PGSA) are used for optimal location and number along with tap setting of the voltage regulators that maintain a smooth voltage profile throughout the network. The aim of this paper is to obtain optimal voltage control with voltage regulators and then to decrease the total cost and losses, to obtain the maximum net savings. The effectiveness of the proposed method is illustrated with 33 bus and 69 bus radial distribution systems and these results are compared with Discrete Particle Swarm Optimization method.
\end{abstract}

Keywords: Plant Growth Simulation Algorithm (PGSA), Radial Distribution Systems (RDS), Voltage Regulator (VR), Load Flow, Power Loss Indicies, Tap Position.

\section{Introduction}

One of the utility's core responsibilities is to maintain consumer's terminal voltage within a suitable range. Hence the utilities must regulate the voltage subject to economic as well as technical considerations. The voltage drop in distribution circuits occur due to current flowing through the line impedances. Voltage drop is higher with lower voltage distribution systems, poor power factor, single-phase circuits, and unbalanced circuits. Electric utilities commonly use both voltage regulators and shunt capacitors to maintain voltages within the specified limits. The shunt capacitors operate in discrete steps while voltage regulators are transformers with variable taps. The voltage change is obtained varying the tap position by a control circuit in the case of voltage regulators. Thus a voltage regulator is used to hold the voltage of a circuit at a predetermined value, within a band which the control equipment is capable of maintaining and within accepted tolerance values for distribution purposes. Voltage Regulators (VR) may be installed at substations or out on distribution feeders on poles, pads, or platforms or in vaults. The shunt capacitors can be fixed or switched type; they are considered integer multiple of a capacitor unit. Regulators have fixed nodal position for all load levels and are characterized by pre-assigned discrete sizes.

A computer algorithm for the voltage control of large radial distribution networks, which takes into account the actual network data such as conductor sizes, lateral and sub-lateral branches as well as load distribution and time variation and handles fast as a total and not in parts making relative approximations, is presented by Salis and Safigianni (2000). It is proposed re-conductoring of currently operating primary distribution networks in order to optimize them technically as much as possible (Salis and Safigianni, 1994 and 1995). Research papers (Grainger and Civanlar, 1985a, 1985b and 1985c) deals with the determination of the optimal solutions for the voltage regulators and capacitors, in order to minimize the peak power and energy losses and provide a smooth voltage profile along a distribution network. The proposed algorithm, for optimal reactive power and voltage control, suitable for 
large distribution networks, starts with implementing a partitioning and Kron's reduction technique in order to reduce the size of the problem (Salama et al., 1996).

The paper by Sen and Larson (1994) addresses what factors to be considered when deciding whether regulators, capacitors, or load balancing or a combination is most appropriate to provide the needed voltage support. The set of papers (Chiang et al., 1995a, $1995 \mathrm{~b}$ and Grainger et al., 1984) formulates the voltage regulator and capacitor problems for general radial distribution systems with lateral branches. In the paper by Mendoza et al. (2005) developed a method for optimal location of Automatic Voltage Regulators in radial distribution networks using simple genetic algorithms. In Augugliaro et al. (2004), the problem of voltage regulation and power losses minimization for automated distribution systems is dealt with evolutionary multi-objective approach.

The proposed method deals with initial selection of voltage regulator buses by using power loss indices (PLI) and Plant Growth Simulation Algorithm (PGSA) is used for optimal location and number along with tap setting of the voltage regulators, which provides a smooth voltage profile along the network. The main objective of this paper is to minimize the number of voltage regulators which in turn reduces the overall cost. The proposed algorithm is tested on 33 bus and 69 bus radial distribution systems.

\section{Load Flow Method}

Load flows provide voltage profiles that help when planning new distribution circuits, adding customers, and tracking down and fixing voltage problems. Most distribution load-flow programs offer a function to plot the voltage as a function of distance from the source. In any radial distribution system, the electrical equivalent of a typical branch, which is connected between buses 1 and 2 having a resistance $r_{(1)}$ and inductive reactance $x_{(1)}$ is shown in Figure 1. Current flowing through branch-1 is given by

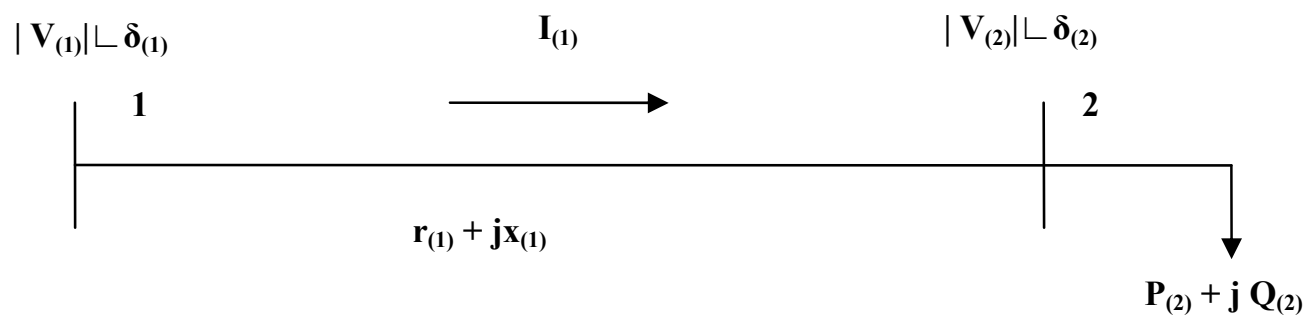

Figure1. Single line diagram of a typical branch

$$
\begin{aligned}
& \mathrm{I}_{(1)}=\left|\mathrm{V}_{(1)}\right|\left|\delta_{(1)}-\right| \mathrm{V}_{(2)}||_{(2)}^{\delta} /\left(\mathrm{r}_{(1)}+\mathrm{jx}_{(1)}\right) \\
& \mathrm{I}_{(1)}=\left(\mathrm{P}_{(2)}-\mathrm{j}_{(2)}\right) / \mathrm{V}_{(2)}{ }^{*}{ }_{(2)}^{\delta}
\end{aligned}
$$

From eqns. (1) and (2),

$$
\frac{\left.\mathrm{P}_{(2)}\right)^{-j Q_{(2)}}}{\left.\left|\mathrm{V}_{(2)}\right|\right|^{-\delta}(2)}=\frac{\left.\left|\mathrm{V}_{(1)}\right|\right|^{-\delta}(1)-\left.\left|\mathrm{V}_{(2)}\right|\right|^{-\delta}(2)}{\mathrm{r}_{(1)}+\mathrm{jx}_{(1)}}
$$

Separating real and imaginary parts, the real part is

$$
\left|\mathrm{V}_{(1)}\right|\left|\mathrm{V}_{(2)}\right| \cos \left(\delta_{(1)}{ }^{-\delta}(2)\right)=\left|\mathrm{V}_{(2)}\right|^{2}+\left\{\mathrm{P}_{(2)} \mathrm{r}_{(1)}+\mathrm{Q}_{(2)} \mathrm{x}_{(1)}\right\}
$$

and the imaginary part is

$$
\begin{aligned}
& \left.\left|\mathrm{V}_{(1)}\right|\left|\mathrm{V}_{(2)}\right| \sin \left(\delta_{(1)}-\delta(2)\right)=\left\{\mathrm{P}_{(2}\right)^{\mathrm{x}}(1)+\mathrm{Q}_{(2)} \mathrm{r}_{(1)}\right\} \\
& \left.\left.\left.\Rightarrow\left|\mathrm{V}_{(2)}\right|^{4}+2\left|\mathrm{~V}_{(2)}\right|^{2}\left(\mathrm{r}_{(1)} \mathrm{P}_{(2)}+\mathrm{x}_{(1)} \mathrm{Q}_{(2)}-0.5\left|\mathrm{~V}_{(1)}\right|^{2}\right)+\left(\mathrm{r}_{(1)}\right)^{2}+\mathrm{x}_{(1)}\right)^{2}\left(\mathrm{P}_{(2}\right)^{2}+\mathrm{Q}_{(2}\right)^{2}\right)=0
\end{aligned}
$$

Eqn. (5) has a straight forward solution and does not depend on the phase angle, which simplifies the problem formulation. In a distribution system, the voltage angle is not so important because the variation of voltage angle from the substation to the tail end of the distribution feeder is only few degrees. Note that from the two solution of $\left|\mathrm{V}_{(2)}\right|^{2}$ only the one considering the sign of the square root of the solution of the quadratic equation gives a realistic value. The same is applicable when solving for $\left|\mathrm{V}_{(2)}\right|$. Therefore from eqn. (5), the solution of $\left|\mathrm{V}_{(2)}\right|$ can be written as 


$$
\left.\left.\left|\mathrm{V}_{(2)}\right|=\left\{\left\{\left(\mathrm{r}_{(1)} \mathrm{P}_{(2)}+\mathrm{x}_{(1)} \mathrm{Q}_{(2)}-0.5\left|\mathrm{~V}_{(1)}\right|^{2}\right)^{2}-\left(\mathrm{r}_{(1)}{ }^{2}+\mathrm{x}_{(1)}\right)^{2}\left(\mathrm{P}_{(2)}\right)^{2}+\mathrm{Q}_{(2)}\right)^{2}\right)\right\}^{1 / 2}-\left(\mathrm{r}_{(1)} \mathrm{P}_{(2)}+\mathrm{x}_{(1)} \mathrm{Q}(2)-0.5\left|\mathrm{~V}_{(1)}\right|^{2}\right)\right\}^{1 / 2}
$$

In general

$\left.\left.\left|\mathrm{V}_{(\mathrm{i}+1)}\right|=\left\{\left\{\left(\mathrm{r}_{(\mathrm{j})} \mathrm{P}_{(\mathrm{i}+1)}+\mathrm{x}_{(\mathrm{j})} \mathrm{Q}_{(\mathrm{i}+1)}-0.5\left|\mathrm{~V}_{(\mathrm{i})}\right|^{2}\right)^{2}-\left(\mathrm{r}_{(\mathrm{j})}{ }^{2}+\mathrm{x}_{(\mathrm{j})}{ }^{2}\right)_{(\mathrm{P}+1)}{ }^{2}+\mathrm{Q}_{(\mathrm{i}+1)}\right)^{2}\right)\right\}^{1 / 2}-\left(\mathrm{r}_{(\mathrm{j})} \mathrm{P}_{(\mathrm{i}+1)}+\mathrm{x}_{(\mathrm{j})} \mathrm{Q}_{(\mathrm{i}+1)}-0.5\left|\mathrm{~V}_{(\mathrm{i})}\right|^{2}\right)\right\}^{1 / 2}$

The active and reactive power losses in branch ' $\mathrm{j}$ ' are given by

$$
\begin{aligned}
& P \operatorname{loss}[j]=\frac{{ }^{r}(j)\left\{P^{2}(i+1)+Q^{2}(i+1)\right\}}{\left|V_{(i+1)}\right|^{2}} \\
& \operatorname{Q} \operatorname{loss}[j]=\frac{x_{(j)}\left\{P^{2}(i+1)+Q^{2}(i+1)\right\}}{\left|V_{(i+1)}\right|^{2}}
\end{aligned}
$$

The total active and reactive power losses of the system are

$$
\begin{aligned}
\mathrm{TPL} & =\sum_{\mathrm{j}=1}^{\mathrm{nd}-1} \mathrm{P} \operatorname{los} \mathrm{s}[\mathrm{j}] \\
\mathrm{TQL} & =\sum_{\mathrm{j}=1}^{\mathrm{nd}-1} \mathrm{Q} \operatorname{loss}[\mathrm{j}]
\end{aligned}
$$

\section{Problem formulation for Voltage Regulator Placement}

Voltage Regulator (VR) or Automatic Voltage Booster (AVB) is essentially an auto transformer consisting of a primary or existing winding connected in parallel with the circuit and a second winding with taps connected in series with the circuit. In order to maintain the voltage profile and to reduce the power losses these are installed in the distribution systems.

- VR provides $10 \%$ boost of voltage

- It boosts voltage in four steps of $2.5 \%$ each and it also boosts voltage in 32 steps of $0.625 \%$ each.

- It has line drop compensation to maintain constant voltage at its location.

- $\quad$ KVA rating $=($ rated voltage $\times \%$ boost of booster $\times$ rated current $) / 100$

- It causes sudden voltage rise in discrete steps at its location leading to better voltage profile and reduction in losses.

The VR problem consists of two sub problems, that of optimal placement and optimal choice of tap setting. The first sub problem determines the location and number of VR to be placed and the second sub problem decides the tap positions of VR. To obtain the optimal location for placing voltage regulators that maintain the voltages within the limits of the RDS so as to maximize an objective function, which consists of capital investment and capitalized energy loss costs. The capital investment is the cost incurred on placement of the Voltage Regulators and the capitalized energy loss costs correspond to the cost of the energy losses in a year. The main steps of the algorithm are reported in the flow chart shown in Figure 2.

The objective function is formulated on the basic idea given in (Pereira C.A.N. and Castro C.A., 2009) as maximizing the net saving function,

Max.F $=\mathrm{K}_{\mathrm{e}} \times \mathrm{P}_{\mathrm{lr}} \times 8760 \times$ LLf $-\mathrm{K}_{\mathrm{VR}} \times \mathrm{N}(\alpha+\beta)$

where $\mathrm{K}_{\mathrm{e}}=$ Energy loss cost factor in Rs./ $\mathrm{kWh}, \quad \mathrm{P}_{\mathrm{lr}}=$ Power loss reduction

LLf $=$ Loss factor $=\left(0.8 x(\text { Load Factor })^{2}\right)+(0.2 \times$ Load Factor $)$

$\mathrm{K}_{\mathrm{VR}}=\mathrm{VR}$ capital cost factor

$\mathrm{N}=$ Number of VRs

$\alpha=$ Regulator Setting for resistance compensation

$\beta=$ Regulator Setting for reactance compensation

3. 1 Selection of tap position of VR's

By finding optimal number and location of VR then tap positions of VR are determined as follows. In general, VR position at bus ' $\mathrm{j}$ ' can be calculated as

$\mathrm{V}_{\mathrm{j}}{ }^{1}=\mathrm{V}_{\mathrm{j}} \pm \operatorname{tap} \times \mathrm{V}_{\text {rated }}$

Tap position (tap) can be calculated by comparing voltage obtained before VR installation with the lower and upper limits of voltage 
'+' for boosting of voltage and '-' for bucking of voltage

The bus voltages are computed by load flow analysis (Das D. et al, 1994) for every change in tap setting of VR's, till all bus voltages are within the specified limits. Then obtain the net savings, with above tap settings for VR's.

3.2 Illustrations of Candidate Node Identification

The node identification method is illustrated by an example of 15-node system. The line and load data of this system is given in (Ghosh and Das, 1994). After running the load flows for base case system, the active power loss is given by $60.34821 \mathrm{~kW}$. By improving voltage at each node equal to upper limit of voltage, one at a time and perform the load flows and calculate the active power loss in each case and also loss reduction. The results are tabulated in Table 1. The most suitable nodes for VR placement are chosen based on the condition PLI greater than a PLI tolerance value between ' 0 ' and ' 1 '. The tolerance value is selected by experimenting with different values in descending order starting from ' 1 '. The best value of the tolerance is the value which gives the highest profit and satisfying the system constraints. The Power Loss Index (PLI) is calculated using eqn. (14) and is tabulated in table 2 .

$$
\text { PL I [i] }=\frac{(\text { Loss reduction [i] - M in im um reduction })}{(\text { M a im um reduction-M inimum reduction })}
$$

\subsection{Algorithm for candidate node identification}

Following algorithm explains the methodology to identify the candidate nodes, which are more suitable for voltage regulator.

- Read radial distribution system data.

- Run the load flows and calculate the base case active power loss.

- By improving the voltage at each node to maximum voltage limit of 1.05 p.u and run the load flows, to calculate the active power losses in each case.

- Calculate the power loss reduction and power loss index using eqn. (14).

- $\quad$ Select the candidate node whose PLI > tolerance.

- Stop.

Table1. Power loss reductions of 15 node system

\begin{tabular}{|c|c|c|}
\hline Node No. & Power Loss $(\mathbf{k W})$ & Loss Reduction $(\mathbf{k W})$ \\
\hline 2 & 45.276 & 15.073 \\
\hline 3 & 47.384 & 12.964 \\
\hline 4 & 56.308 & 4.0405 \\
\hline 5 & 58.398 & 1.9502 \\
\hline 6 & 58.484 & 1.8639 \\
\hline 7 & 57.591 & 2.7573 \\
\hline 8 & 59.216 & 1.1325 \\
\hline 9 & 58.995 & 1.3529 \\
\hline 10 & 57.533 & 2.815 \\
\hline 11 & 56.427 & 3.9216 \\
\hline 12 & 59.018 & 1.33 \\
\hline 13 & 59.822 & 0.52648 \\
\hline 14 & 59.602 & 0.7466 \\
\hline 15 & 58.856 & 1.4926 \\
\hline
\end{tabular}

Table2. The Power Loss Indices of 15 node system

\begin{tabular}{|c|c|c|c|c|c|c|c|}
\hline Node No. & 2 & 3 & 4 & 5 & 6 & 7 & 8 \\
\hline PLI & 1.00000 & 0.85503 & 0.24158 & 0.09788 & 0.09195 & 0.15336 & 0.04166 \\
\hline Node No. & 9 & 10 & 11 & 12 & 13 & 14 & 15 \\
\hline PLI & 0.05681 & 0.15733 & 0.23341 & 0.05524 & 0.00000 & 0.01513 & 0.06642 \\
\hline
\end{tabular}




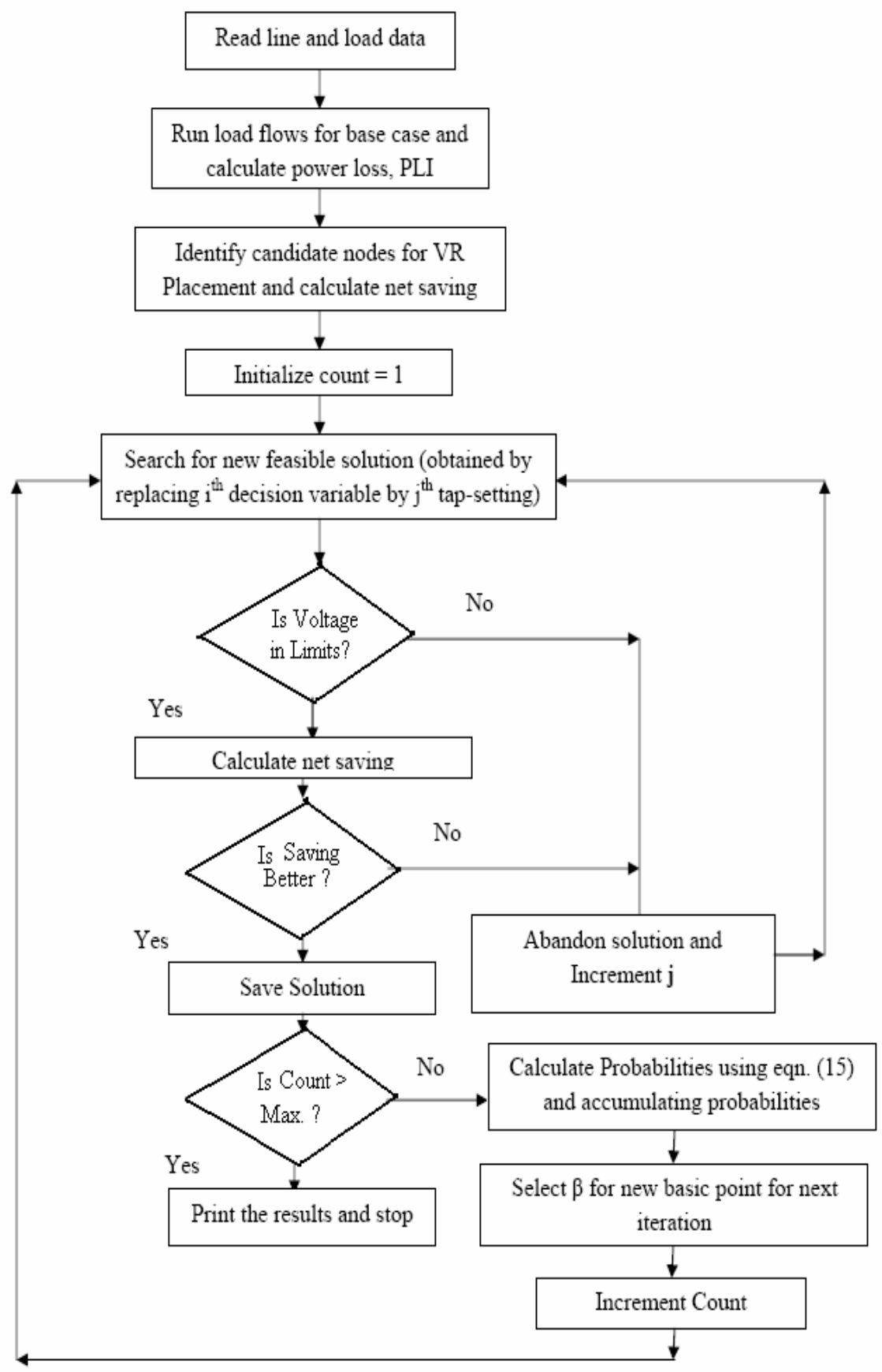

\section{Implementation of PGSA to Voltage Regulator Placement}

Figure2. Flow chart

The plant growth simulation algorithm (Chun et al., 2008) which characterizes the growth mechanism of plant phototropism is a bionic random algorithm. It looks at the feasible region of integer programming as the growth environment of a plant and determines the probabilities to grow a new branch on different nodes of a plant according to the change of the objective function, and then makes the model, which simulates the growth process of a plant, rapidly grow towards the light source (global optimum solution).

\subsection{Growth Laws of a Plant}

The following facts have been proved by the biological experiments.

1) The higher the morphactin concentration of a node, the greater the probability to grow a new branch on the node. 
2) The morphactin concentration of any node on a plant is not given beforehand and is not fixed; it is determined by the environmental information of the node, and the environmental information of a node depends on its relative position on the plant.

4.2 Probability Model of Plant Growth

By simulating the growth process of plant phototropism, a probability model is established. In the model, a function $g(Y)$ is introduced for describing the environment of the node $\mathrm{Y}$ on a plant. The smaller the value of $\mathrm{g}(\mathrm{Y})$, the better the environment of the node $\mathrm{Y}$ for growing a new branch. The main outline of the model is as follows: A plant grows a trunk $\mathrm{M}$ from its root $\mathrm{B}_{0}$. Assuming there are k nodes $\mathrm{B}_{\mathrm{M} 1}, \mathrm{~B}_{\mathrm{M} 2}, \mathrm{~B}_{\mathrm{M} 3} \ldots \ldots . . . \mathrm{B}_{\mathrm{Mk}}$ that have better environment than the root $\mathrm{B}_{0}$ on the trunk $\mathrm{M}$, which means the function $g(Y)$ of the nodes $B_{M 1}, B_{M 2}, B_{M 3} \ldots \ldots . . B_{M k}$ and $B_{0}$ satisfy $g\left(B_{M i}\right)<g\left(B_{0}\right)(i=1,2,3 \ldots k)$, then the morphactin concentrations $\mathrm{C}_{\mathrm{M} 1}, \mathrm{C}_{\mathrm{M} 2}, \mathrm{C}_{\mathrm{M} 3} \ldots \ldots . . \mathrm{C}_{\mathrm{Mk}}$ of the nodes $\mathrm{B}_{\mathrm{M} 1}, \mathrm{~B}_{\mathrm{M} 2}, \mathrm{~B}_{\mathrm{M} 3} \ldots \ldots . . \mathrm{B}_{\mathrm{Mk}}$ can be calculated using

$$
\begin{aligned}
& \mathrm{C}_{M i}=\frac{\mathrm{g}\left(\mathrm{B}_{0}\right)-\mathrm{g}\left(\mathrm{B}_{\mathrm{Mi}}\right)}{\Delta_{1}}(\mathrm{i}=1,2,3 \ldots \mathrm{k}) \\
& \Delta_{1}=\sum_{\mathrm{i}=1}^{\mathrm{k}}\left(\mathrm{g}\left(\mathrm{B}_{0}\right)-\mathrm{g}\left(\mathrm{B}_{\mathrm{Mi}}\right)\right)
\end{aligned}
$$

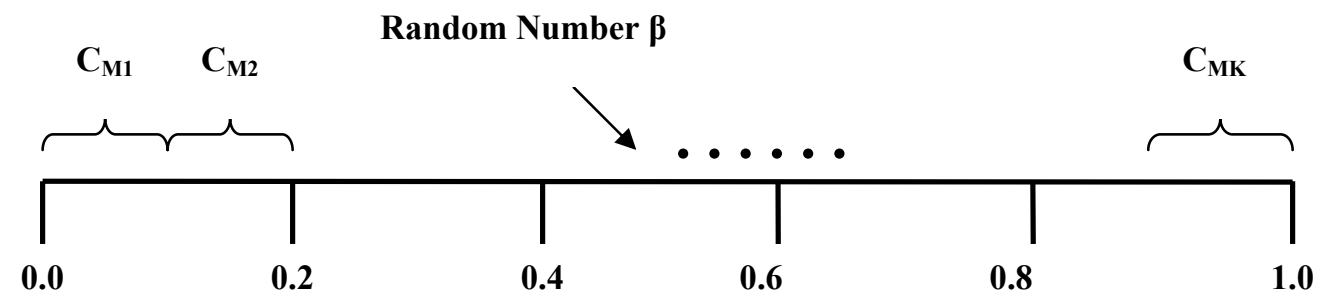

Figure3. Morphactin concentration state space

The significance of (15) is that the morphactin concentration of a node is not dependent on its environmental information but also depends on the environmental information of the other nodes in the plant, which really describes the relationship between the morphactin concentration and the environment.

Equation (15) can be used to derivate $\sum_{i=1}^{\mathrm{k}} \mathrm{C}_{\mathrm{Mi}}=1$, which means that the morphactin concentrations $\mathrm{C}_{\mathrm{M} 1}, \mathrm{C}_{\mathrm{M} 2}, \mathrm{C}_{\mathrm{M} 3} \ldots \ldots \ldots . . \mathrm{C}_{\mathrm{Mk}}$ of the nodes $B_{M 1}, B_{M 2}, B_{M 3} \ldots \ldots . . . B_{M k}$ form a state space shown in Figure 3. Selecting a random number $\beta$ in the interval [0, 1], $\beta$ is like a ball thrown to the interval $[0,1]$ and will drop into one of $C_{M 1}, C_{M 2}, C_{M 3} \ldots \ldots . . . C_{M k}$ in Figure 3, then the corresponding node that is called the preferential growth node will take priority of growing a new branch in the next step. In other words, $\mathrm{B}_{\mathrm{MT}}$ will take priority of growing a new branch if the selected $\beta$ satisfies $0 \leq \beta \leq \sum_{i=1}^{\mathrm{T}} \mathrm{C}_{\mathrm{Mi}}(\mathrm{T}=1)$ or $\sum_{\mathrm{i}=1}^{\mathrm{T}-1} \mathrm{C}_{\mathrm{Mi}}<\beta \leq \sum_{\mathrm{i}=1}^{\mathrm{T}} \mathrm{C}_{\mathrm{Mi}}(\mathrm{T}=2,3 \ldots \mathrm{k})$. For example, if random number $\beta$ drops between an interval [1 2 ], which means $\sum_{\mathrm{i}=1}^{1} \mathrm{C}_{\mathrm{Mi}}<\beta \leq \sum_{\mathrm{i}=1}^{2} \mathrm{C}_{\mathrm{Mi}}$, then the node will grow a new branch $\mathrm{m}$.

\subsection{A complete algorithm for the proposed method of Voltage regulator placement}

1. Input the system data such as line and load details of the distribution system, constraints limits etc.

2. Form the search domain by identifying the no. of candidate buses as decision variables for the voltage regulator which corresponds to the length of the trunk and the branch of a plant;

3. Identify the candidate nodes for voltage regulator placement using Power Loss Indices.

4. Give the initial solution $X_{o}$ ( $X_{o}$ is a vector with the length of no. of buses required for VR placement) which corresponds to the root of a plant, and calculate the initial value objective function (net saving);

5. Let the initial value of the basic point $\mathrm{X}^{\mathrm{b}}$, which corresponds to the initial preferential growth node of a plant, and the initial value of optimization $\mathrm{X}^{\text {best }}$ equal to $\mathrm{X}_{\mathrm{o}}$, and let $\mathrm{F}^{\text {best }}$ that is used to save the objective function value of the best solution $\mathrm{X}^{\text {best }}$ be equal to $f\left(X_{o}\right)$, namely, $X^{b}=X^{\text {best }}=X_{o}$ and $F^{\text {best }}=f\left(X_{o}\right)$;

6. Initialize iteration count, count $=1$;

7. Search for new feasible solutions: Starting from basic point $X^{b}=\left[x_{1}{ }^{b}, x_{2}{ }^{b} . x_{i}{ }^{b} \ldots x_{n}{ }^{b}\right]$, where $X^{b}$ corresponds to the initial tap setting corresponding to each regulator. ( $\mathrm{n}$ is no. of candidate buses for regulator placement).

Step (7a): For $\mathrm{j}=\mathrm{n}$ to $\mathrm{m}$ (with step length one) where $\mathrm{n}$ and $\mathrm{m}$ are minimum and maximum tap- setting of regulator respectively.

Step (7b): Let $\mathrm{X}^{\mathrm{p}}$ be a new solution obtained by replacing $\mathrm{i}^{\text {th }}$ decision variable by $\mathrm{j}^{\text {th }}$ tap-setting.

Step (7c): For the found solution $\mathrm{X}^{\mathrm{p} \text { check }}$ it out the constraints, if it satisfies the go to next step, otherwise abandon the possible solution $\mathrm{X}^{\mathrm{p}}$. 
Step (7d): Calculate the objective function $f\left(X^{p}\right)$, and compare $f\left(X^{p}\right)>f\left(X^{b}\right)$, if it does not satisfy abandon the possible solution $\mathrm{X}^{\mathrm{p}}$ and increment ' $\mathrm{j}$ ' then go to step ( $\left.7 \mathrm{~b}\right)$.

8. Save the best possible solution from obtained feasible solutions.

9. If count $>\mathrm{N}_{\max }$ go to step 13; otherwise go to next step.

10. Calculate the probabilities $C_{1}, C_{2}, \ldots$ Ck of feasible solutions $X^{1}, X^{2}, X^{3}, \ldots X^{k}$ by using eqn. (15), which corresponds to determining the morphactin concentration of the nodes of a plant.

11. Calculate the accumulating probabilities $\sum \mathrm{C}_{1}, \sum \mathrm{C}_{2}, \ldots \sum \mathrm{C}_{\mathrm{k}}$ of the solutions $\mathrm{X}^{1}, \mathrm{X}^{2}, \ldots \mathrm{X}^{\mathrm{k}}$. Select a random number $\beta$ from the interval $[01], \beta$ must belong to one of the intervals $\left[0 \sum \mathrm{C}_{1}\right],\left[\sum \mathrm{C}_{1}, \sum \mathrm{C}_{2}\right], \ldots,\left[\sum \mathrm{C}_{\mathrm{k}-1}, \sum \mathrm{C}_{\mathrm{k}}\right]$, the accumulating probability of which is equal to the upper limit of the corresponding interval, and it will be the new basic point $\mathrm{X}^{\mathrm{b}}$ for the next iteration, which corresponds to the new preferential growth node of a plant for next step.

12. Increment count by count +1 and return to step 7 ;

13. Output the results and stop.

\section{Illustrative Examples}

The effectiveness of the proposed method is illustrated with two examples.

\subsection{Example-1}

Consider 33 bus practical radial distribution system, the line and load data is given (Baran and Wu, 1989a). For the positioning of voltage regulators, the upper and lower bounds of voltage are taken as $\pm 5 \%$ of base value. The voltage regulators are of $11 \mathrm{kV}$, 200 MVA with 32 steps of $0.625 \%$ each. The total profit in a year for different PLI tolerance values for 33-node system is shown in Table 3.

Table3. Total profit in a year for different PLI tolerance values for 33-node system

\begin{tabular}{|c|c|c|}
\hline PLI & Nodes & Max. Net Saving(Rs.) \\
\hline 0.5 & $2,3,4,5,6,26,27,28,29$ & 1511919.56 \\
\hline $\mathbf{0 . 6}$ & $\mathbf{2 , 3 , 4 , 5 , 6}$ & $\mathbf{2 5 1 8 9 7 8 . 8 1}$ \\
\hline 0.75 & 5,6 & 2442460.81 \\
\hline
\end{tabular}

Table4. Summary results of 33-node radial distribution system

\begin{tabular}{|c|c|c|c|c|c|c|}
\hline \multirow{2}{*}{\multicolumn{2}{|c|}{ Aspect }} & \multirow[t]{2}{*}{ Without VR } & \multicolumn{4}{|c|}{$\begin{array}{c}\text { With VR } \\
\text { Using }\end{array}$} \\
\hline & & & \multicolumn{2}{|c|}{ DPSO } & \multicolumn{2}{|c|}{ PGSA } \\
\hline \multirow{6}{*}{\multicolumn{2}{|c|}{ Optimal locations and Size (kVAr) }} & & Node & $\begin{array}{l}\text { Tap } \\
\text { Set }\end{array}$ & Node & $\begin{array}{l}\text { Tap } \\
\text { Set }\end{array}$ \\
\hline & & & 2 & 0 & 2 & 0 \\
\hline & & & 3 & 0 & 3 & 0 \\
\hline & & & 4 & 0 & 4 & 0 \\
\hline & & & 5 & 12 & 5 & 12 \\
\hline & & & 6 & 1 & 6 & 2 \\
\hline \multicolumn{2}{|c|}{ Real power loss $(\mathrm{kW})$} & 202.7070 & \multicolumn{2}{|c|}{154.299} & \multicolumn{2}{|c|}{152.17} \\
\hline \multicolumn{2}{|c|}{ Reactive power loss (kVAr) } & 135.24 & \multicolumn{2}{|c|}{103.37} & \multicolumn{2}{|c|}{101.88} \\
\hline \multirow{3}{*}{ Net Saving(Rs.) } & Best & & \multicolumn{2}{|c|}{2325011.44} & \multicolumn{2}{|c|}{2442460.81} \\
\hline & Worst & & \multicolumn{2}{|c|}{0} & \multicolumn{2}{|c|}{2377865.44} \\
\hline & Average & & \multicolumn{2}{|c|}{2071586.93} & \multicolumn{2}{|c|}{2438725.26} \\
\hline \multicolumn{2}{|c|}{ Percentage loss reduction } & ------- & \multicolumn{2}{|c|}{23.88} & \multicolumn{2}{|c|}{24.93} \\
\hline \multicolumn{2}{|c|}{ Min.Voltage (p.u) } & 0.9130 & \multicolumn{2}{|c|}{0.971444} & \multicolumn{2}{|c|}{0.971532} \\
\hline \multicolumn{2}{|c|}{ Voltage Regulation (\%) } & 8.7 & \multicolumn{2}{|c|}{2.86} & \multicolumn{2}{|c|}{2.85} \\
\hline \multicolumn{2}{|c|}{ No. of times best solution occurred } & ------ & \multicolumn{2}{|c|}{54} & \multicolumn{2}{|c|}{94} \\
\hline \multicolumn{2}{|c|}{ Execution time (Sec) } & ------- & \multicolumn{2}{|c|}{19.129183} & \multicolumn{2}{|c|}{32.056219} \\
\hline
\end{tabular}


In the Load flow solution for 33 bus RDS without and with voltage regulators, it is found that most of the bus voltages except buses 1 to 5 are violate the lower limit of 0.95 p.u. Ideally voltage regulators are to be installed at all buses except at bus 1 to 5 . However, in practice, it is not economical to have more number of voltage regulators at all buses to get the voltages within specified limits. Hence by applying proposed PGSA algorithm, the required optimal number of voltage regulators that will maintain the voltage profile within above limits is determined. From candidate node identification technique, the optimal buses for voltage regulator placement are 2,3,4,5 and 6 . From PGSA method the tap positions are $\{0,0,0,12,2\}$, at nodes $2,3,4,5$, and 6 respectively. At bus 2, 3, 4 the tap position is 0 means that the voltage regulator at bus 2, 3, 4 can be omitted and at buses 5 and 6 the voltage regulator is in boost position by $7.5 \%$ and $1.25 \%$ respectively. It is observed that from Table 4 , without voltage regulators in the system the power loss is $202.707 \mathrm{~kW}$ and percentage voltage regulation is $8.7 \%$. With voltage regulators the power loss is $152.171262 \mathrm{~kW}$ and percentage voltage regulation is $2.8468 \%$. The net saving is Rs. $2442460.81 /-$ with voltage regulators at optimal locations. The simulation results of voltage profile and objective function are shown in Figure $4 \&$ Figure 5 respectively. The results with proposed PGSA are compared with DPSO method (Rao J.V. and Sivanagaraju S., 2008). The power losses are reduced and minimum voltage is improved.

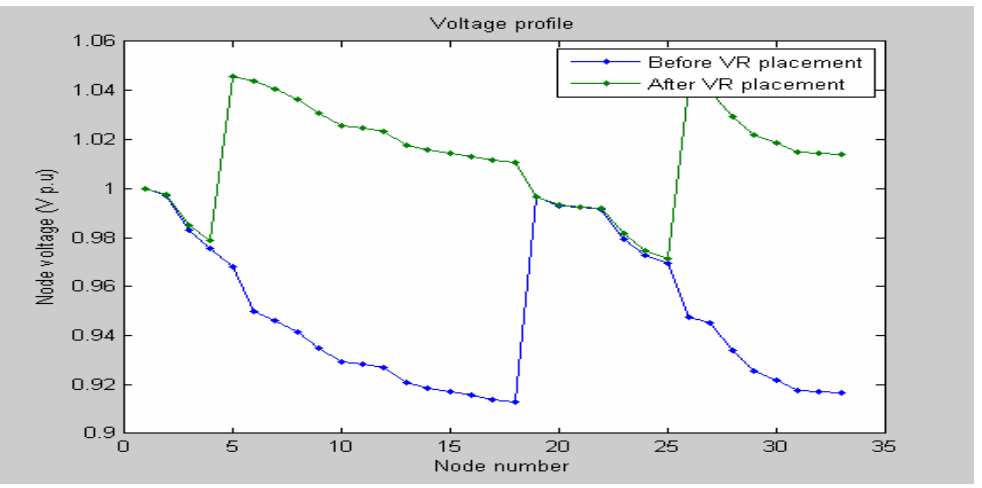

Figure4. Voltage Profile for 33-node radial distribution system before and after voltage regulator placement

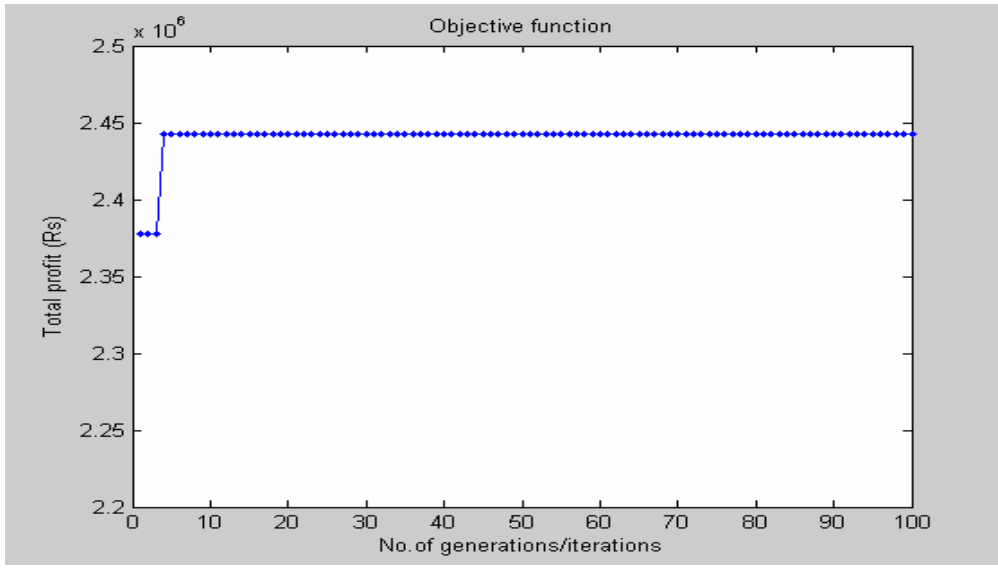

\subsection{Example-2}

Figure5. Objective function for 33-node radial distribution system

Consider 69 bus radial distribution system, the line and load data of which is given in (Baran M. E. and Wu F. F., 1989b).

Table5. Total profit in a year for different PLI tolerance values for 69-node system

\begin{tabular}{|c|c|c|}
\hline PLI & Nodes & Max.Net Saving(Rs.) \\
\hline 0.7 & $7,8,55,56,57,58,59,60$ & 2540099.99 \\
\hline $\mathbf{0 . 8}$ & $\mathbf{5 6 , 5 7 , 5 8 , 5 9 , 6 0}$ & $\mathbf{3 4 9 9 6 2 6 . 1 6}$ \\
\hline 0.9 & $57,58,59,60$ & 3357460.09 \\
\hline
\end{tabular}

The voltage profile before and after placing voltage regulators is shown in Figure 6. The total profit in a year for different PLI tolerance values for 69-node system is shown in table 5. From candidate node identification method the suitable buses for voltage regulator placement are 56, 57, 58, 59 and 60 . From PGSA method the tap positions are $\{0,+7,0,0,+12\}$, at nodes 56,58 and 59 the tap position is 0 means that the voltage regulator at these buses can be omitted. 


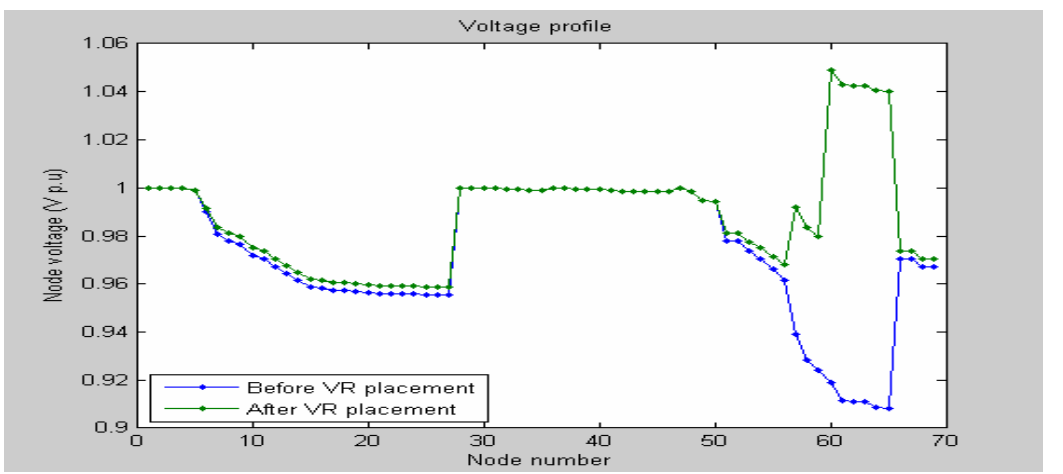

Figure6. Voltage Profile for 69-node radial distribution system before and after voltage regulator placement

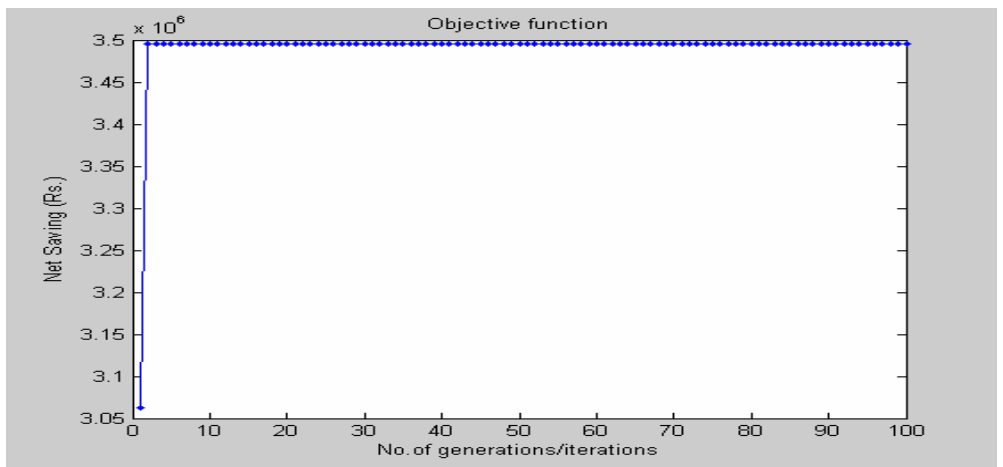

Figure7. Objective function for 69-node radial distribution system

Table6. Summary results of 69-node radial distribution system

\begin{tabular}{|c|c|c|c|c|c|c|}
\hline \multirow{2}{*}{\multicolumn{2}{|c|}{ Aspect }} & \multirow{2}{*}{$\begin{array}{c}\text { Without } \\
\text { VR }\end{array}$} & \multicolumn{4}{|c|}{$\begin{array}{c}\text { With VR } \\
\text { Using }\end{array}$} \\
\hline & & & \multicolumn{2}{|c|}{ DPSO } & \multicolumn{2}{|c|}{ PGSA } \\
\hline \multirow{6}{*}{\multicolumn{2}{|c|}{ Optimal locations and Size (kVAr) }} & & Node & $\begin{array}{l}\text { Tap } \\
\text { Set }\end{array}$ & Node & $\begin{array}{l}\text { Tap } \\
\text { Set }\end{array}$ \\
\hline & & & 56 & 0 & 56 & 0 \\
\hline & & & 57 & 0 & 57 & 7 \\
\hline & & & 58 & 16 & 58 & 0 \\
\hline & & & 59 & -12 & 59 & 0 \\
\hline & & & 60 & 16 & 60 & 12 \\
\hline \multicolumn{2}{|c|}{ Real power loss (kW) } & 225.4386 & \multicolumn{2}{|c|}{156.40} & \multicolumn{2}{|c|}{155.75} \\
\hline \multicolumn{2}{|c|}{ Reactive power loss (kVAr) } & 107.12 & \multicolumn{2}{|c|}{76.38} & \multicolumn{2}{|c|}{76.17} \\
\hline \multirow{3}{*}{ Net Saving (Rs.) } & Best & & \multicolumn{2}{|c|}{3290175.73} & \multicolumn{2}{|c|}{3499626.16} \\
\hline & Worst & & \multicolumn{2}{|c|}{2638711.42} & \multicolumn{2}{|c|}{3062917.49} \\
\hline & Average & & \multicolumn{2}{|c|}{3275802.49} & \multicolumn{2}{|c|}{3490891.99} \\
\hline \multicolumn{2}{|c|}{ Percentage loss reduction } & ------- & \multicolumn{2}{|c|}{30.62} & \multicolumn{2}{|c|}{30.91} \\
\hline \multicolumn{2}{|c|}{ Min.Voltage (p.u) } & 0.908308 & \multicolumn{2}{|c|}{0.950295} & \multicolumn{2}{|c|}{0.958787} \\
\hline \multicolumn{2}{|c|}{ Voltage Regulation (\%) } & 9.1692 & \multicolumn{2}{|c|}{4.97} & \multicolumn{2}{|c|}{4.12} \\
\hline \multicolumn{2}{|c|}{ No. of times best solution occurred } & ------- & \multicolumn{2}{|c|}{90} & \multicolumn{2}{|c|}{98} \\
\hline \multicolumn{2}{|c|}{ Execution time (Sec) } & ------- & \multicolumn{2}{|c|}{26.913390} & \multicolumn{2}{|c|}{30.763057} \\
\hline
\end{tabular}

It is observed that from Table.6, without voltage regulators in the system the power loss is $225.4386 \mathrm{~kW}$ and percentage voltage regulation is $9.1692 \%$. With voltage regulators at buses only from 57 and 60 , the power loss is $155.7473 \mathrm{~kW}$ and percentage 
voltage regulation is $4.1213 \%$. The net saving is Rs. 3499626.16 with voltage regulators at optimal locations by PGSA whereas it is Rs. 3290175.73 using DPSO method. The minimum voltage is also improved from 0.950295 to 0.958787 using PGSA. The simulation result of objective function for 69 node radial distribution system is shown in Figure 7.

\section{Conclusion}

In radial distribution systems it is necessary to maintain voltage levels within limits at various buses. This paper aims at discussing the maintenance of voltage levels by using voltage regulators in order to improve the voltage profile and to maximize the net savings. The proposed method deals with initial selection of VR by using power loss indices (PLI) and then PGSA has been used for optimal location and number along with tap setting of the voltage regulators to maintain voltage profile within the desired limits and reduces the losses. The proposed algorithm is tested with two systems consisting of 33 bus and 69 bus radial distribution systems and the results are compared with DPSO. The results are found to be better compared to DPSO.

\section{Nomenclature}

VR Voltage Regulator

Min. Minimum

Eqn. Equation

PLI Power Loss Index

DPSO Discrete Particle Swarm Optimization

\section{References}

Augugliaro A., Dusonchet L., Favuzza S., Sanseverino E.R., 2004. Voltage regulation and power loss minimization in automated distribution networks by an evolutionary multi-objective approach, IEEE Transactions on Power Systems, Vol. 19, No. 3, pp. 1516-1527.

Baran M. E. and Wu F. F., 1989a. Optimal capacitor placement on radial distribution system, IEEE Trans. on Power Delivery, Vol. 4, No. 1, pp. 725-734.

Baran M. E. and Wu F. F., 1989b. Optimal sizing of capacitors placed on a radial distribution system, IEEE Trans. on Power Delivery, Vol. 4, No. 1, pp. 735-743.

Chiang H. D., Wang I. C., and Darling G., 1995a. Optimal capacitor placement, replacement and control in large-scale unbalanced distribution systems: system solution algorithms a numerical studies, IEEE Trans. on PWRS, Vol. 10, No. 1, pp. $363-369$.

Chiang H. D., Wang I. C., and Darling G., 1995b. Optimal capacitor placement, replacement and control in large-scale unbalanced distribution systems: system modeling and a new formulation, IEEE Trans. on PWRS, Vol. 10, No. 1, pp. $356-$ 362.

Das D., Nagi H.S., Kothari D.P., 1994. Novel method for solving radial distribution system, IEE Proc. Generation, Transmission, Distribution, Vol. 141, No. 4, pp.291-298.

Ghosh S. and Das D., 1994. Method for load flow solution of radial distribution networks, IEE part C, Vol. 146 (4), pp. 641.

Grainger J. J. and Civanlar S., 1985a. Volt/Var control on distribution system with lateral branches using shunt capacitors and voltage regulators, Part I: the overall problem, IEEE Trans. on PAS, Vol. 104, No. 11, pp.3278-3283.

Grainger J. J. and Civanlar S., 1985b. Volt/Var control on distribution system with lateral branches using shunt capacitors and voltage regulators, Part II: the solution method, IEEE Trans. on PAS, Vol. 104, No. 11, pp. 3284-3290.

Grainger J. J. and Civanlar S., 1985c. Volt/Var control on distribution system with lateral branches using shunt capacitors and voltage regulators, Part III: the numerical results, IEEE Trans .on PAS, Vol. 104, No. 11, pp. 3291-3297.

Grainger J. J., Civanlar S., Clinard K. N., and Gale L. I., 1984. Optimal voltage dependent continuous time control of reactive power on primary feeders, IEEE Trans. on PAS, Vol. 103, No. 9, pp. 2714-2722.

Mendoza J., Lopez E., Morales D., Lopez R., Lopez M., Vannier J.C., 2005. Optimal location of voltage regulators in radial distribution networks using genetic algorithms, $15^{\text {th }}$ Power Systems Computation Conference, Liege, Belgium, August 22-26.

Pereira C.A.N. and Castro C.A., 2009. Optimal placement of voltage regulator in distribution systems, IEEE Bucharest Power Tech Conference, Bucharest, Romania, June $28^{\text {th }}-$ July $2^{\text {nd }}$.

Rao J.V. and Sivanagaraju S., 2008. Optimal voltage regulator placement using discrete particle swarm optimization (DPSO), International Review of Electrical Engineering, Vol. 3. No. 3, pp. 525-53.

Salama M.M.A., Manojlovic N., Quintana V. H. and Chikhani A. Y., 1996. Real-time optimal reactive power control for distribution networks, International Journal of Electrical Power and Energy Systems, Vol. 18, No. 3, pp. 185-193.

Salis G. J. and Safigianni A.S., 2000. Optimal voltage regulator placement in a radial power distribution network, IEEE Transactions on Power Systems, Vol. 15, No. 2, pp. 879-886. 
Salis G. and Safigianni A., 1994. Economically justified modification of a radial network to an optimal Form, Advances in Engineering Software, Vol. 21, No. 1, pp. 49-65.

Salis G. and Safigianni A., 1995. Economical optimization of a radial power network based on voltage drop criterion, Advances in Engineering Software, Vol. 22, No. 1, pp. 1-20.

Sen, P. K. and Larson, S. L., 1994. Fundamental concepts of regulating distribution system voltages, IEEE Rural Electric Power Conference, Department of Electrical Engineering, Colorado University, Denver, Colorado.

Wang Chun, Cheng H. Z. and Yao L. Z, 2008. Optimization of network reconfiguration in large distribution systems using plant growth simulation algorithm, DRPT 2008 Conference, Nanjing, China, pp.771-774, 6-9, April.

\section{Biographical Notes}

Dr. S. Sivanaga Raju received his Masters degree in 2000 from IIT, Kharagpur and did his Ph.D from J.N.T. University in 2004. He is currently working as Associate Professor in the Department of Electrical \& Electronics Engineering, J.N.T.U.K. College of Engineering (Autonomous) Kakinada, Andhra Pradesh, India. He had received two national awards (Pandit Madan Mohan Malaviya memorial prize award and Best paper prize award) from the Institute of Engineers (India) for the year 2003-04. He is referee for IEE Proceedings - Generation Transmission and Distribution and International journal of Emerging Electrical Power System. He has 50 publications in National and International journals and conferences to his credit. His areas of interest are in Distribution Automation, Genetic Algorithm application to distribution systems and power system.

Prof. P.V.V Rama Rao obtained his B.Tech degree in Electrical \& Electronics Engineering from J.N.T.University Hyderabad in 1998. He obtained his M.Tech degree in Electrical Power Engineering from J.N.T.University Hyderabad. He is presently working as Professor \& Head in the department of Electrical and Electronics Engineering in Arjun College of Technology \& Science, Hyderabad, Andhra Pradesh, India. His areas of interest are Power Systems, Electrical Distribution Systems, Simulation of Electrical Systems.

Received May 2010

Accepted June 2010

Final acceptance in revised form November 2010 